\title{
Simulation and Analysis of Induced Current of HV Parallel Reactor Disconnector for 500kV Double Circuit Line on the Same Tower
}

\author{
LI Haisheng ${ }^{1 *}$, ZHANG Jianquan ${ }^{1}$, FANG Boyi ${ }^{1}$, LIU Bin ${ }^{1}$, FENG Bin ${ }^{2}$ \\ ${ }^{1}$ Liuzhou Bureau, China Southern Power Grid EHV Power Transmission Company, Liuzhou, Guangxi,545006, China \\ ${ }^{2}$ Electric Power Research Insitute. CSG, Guangzhou, Guangdong, 510610, China
}

\begin{abstract}
The $500 \mathrm{kV}$ double circuit line with HV parallel reactors has a long outage time in ice melting operation.In this paper, we discussed the possibility of directly switching HV parallel reactor disconnector under the cold standby state,in order to further optimize the operation mode of DC ice melting line.We calculated the induced current of the HV parallel reactors disconnector in the 500kV LG A and B lines, and analyzed the related factors. We also calculate the overvoltage level of the HV parallel reactor disconnector, and put forward the parameter requirements, which provides reference for the type selection.
\end{abstract}

\section{Introduction}

With the improvement of DC ice melting technology, it has become an important way for line melting. However, the research on the ice melting device itself is more focused, and less research is done on the process of DC melting.Currently, in the DC melting process of a line with HV parallel reactor, it is necessary to isolate the HV parallel reactor from the line first, and then insert the HV parallel reactors into the system after the end of melting ice. The operation process is as follows: closing the line grounding switch, pulling the $\mathrm{HV}$ parallel reactor disconnector, opening the line grounding switch, with lasted 40 minutes, and vice versa. If we can directly pull the HV parallel reactor disconnector while the line is in cold standby state, the single operation takes less than ten minutes, thus reducing the whole melting process by nearly an hour. It has greatly reduced the time of the line shutdown.

For the $500 \mathrm{kV}$ double-circuit line on the same tower, when one line is cut off and the other line is running, induced voltage and induced current are generated in the outage line due to electrostatic coupling and electromagnetic coupling between the two lines. When there is a HV parallel reactor on the outage line, due to the effect of the $\mathrm{HV}$ parallel reactor compensating the line-to-ground capacitance, the static induced voltage on the outage line of the operating line is significantly increased.Before the reactor of the outage line is isolated, there will be a large induced current flowing through the reactor disconnector. At present, it is not known whether the reactor disconnector has the ability of switching induced current. Therefore, it is necessary to study the electromagnetic induction under the condition of reactor of $500 \mathrm{kV}$ transmission line.

This paper took $500 \mathrm{kV}$ LG A and B lines as an example. We simulated the electromagnetic induction of the running line to the outage line, and and calculated the inductive current flowing through the reactor disconnector of the outage line. The factors such as transmission power, operating line voltage, height of conductor to ground and soil resistivity were also analyzed. The overvoltage of $\mathrm{HV}$ parallel reactor switched on and off by disconnector was simulated.

\section{Calculation parameter selection}

The $500 \mathrm{kV}$ LG A and B lines are erected on the same tower and the line length is $135.88 \mathrm{~km}$. The $500 \mathrm{kV} \mathrm{LG} \mathrm{A}$ and $\mathrm{B}$ lines are equipped with a group of $3 \times 40 \mathrm{Mvar} \mathrm{HV}$ parallel reactors on the side of $G$ Substation. The reactance value of neutral reactor is $1014.2 \pm 11 \% \Omega$.

\subsection{Selection of tower type}

Drum tower is used in the $500 \mathrm{kV} \mathrm{LG} \mathrm{A}$ and B lines. One-half of the full-line tower adopts the SZT20 straight tower, which is selected in simulation calculation. The structure, dimensions and layout of the pattern SZT20 tower are shown in Figure 1.

\subsection{Selection of span and grounding line sag}

The span distribution of the $500 \mathrm{kV}$ LG A and B lines is complex. In the calculation, the average span is about $400 \mathrm{~m}$, the length of the hanging string is $5 \mathrm{~m}$, the wire arc is $12 \mathrm{~m}$, and the ground arc is $9 \mathrm{~m}$.

*Corresponding author's e-mail: 57116626@qq.com 


\subsection{Parameters of wires and ground wires}

Two kinds of conductors are used in $500 \mathrm{kV}$ LG A-B line, $4 *$ LGJ-400/50 and $4 *$ LGJ-400/35. The $500 \mathrm{kV}$ LG A-B line has been transposed three times, and the line is divided into four sections. The length of each transposition section is $23.394 \mathrm{~km}, 46.944 \mathrm{~km}, 44.785$ $\mathrm{km}$ and $20.757 \mathrm{~km}$. It is shown in Figure 2.

One ground wire is OPGW fiber composite ground wire, which is grounded tower by tower. The other ground wire is ordinary ground wire, the models are lbgj-100-30ac, gj-80 and gj-100, and the common ground wire adopts segmented ground mode.

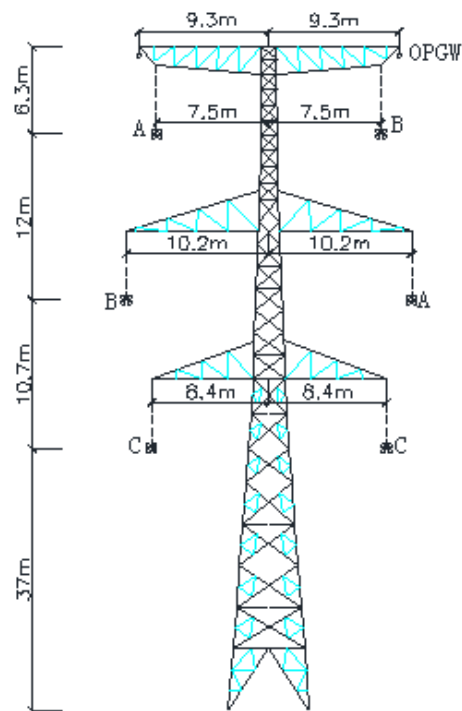

Figure 1. Structure and size of SZT20 linear tower

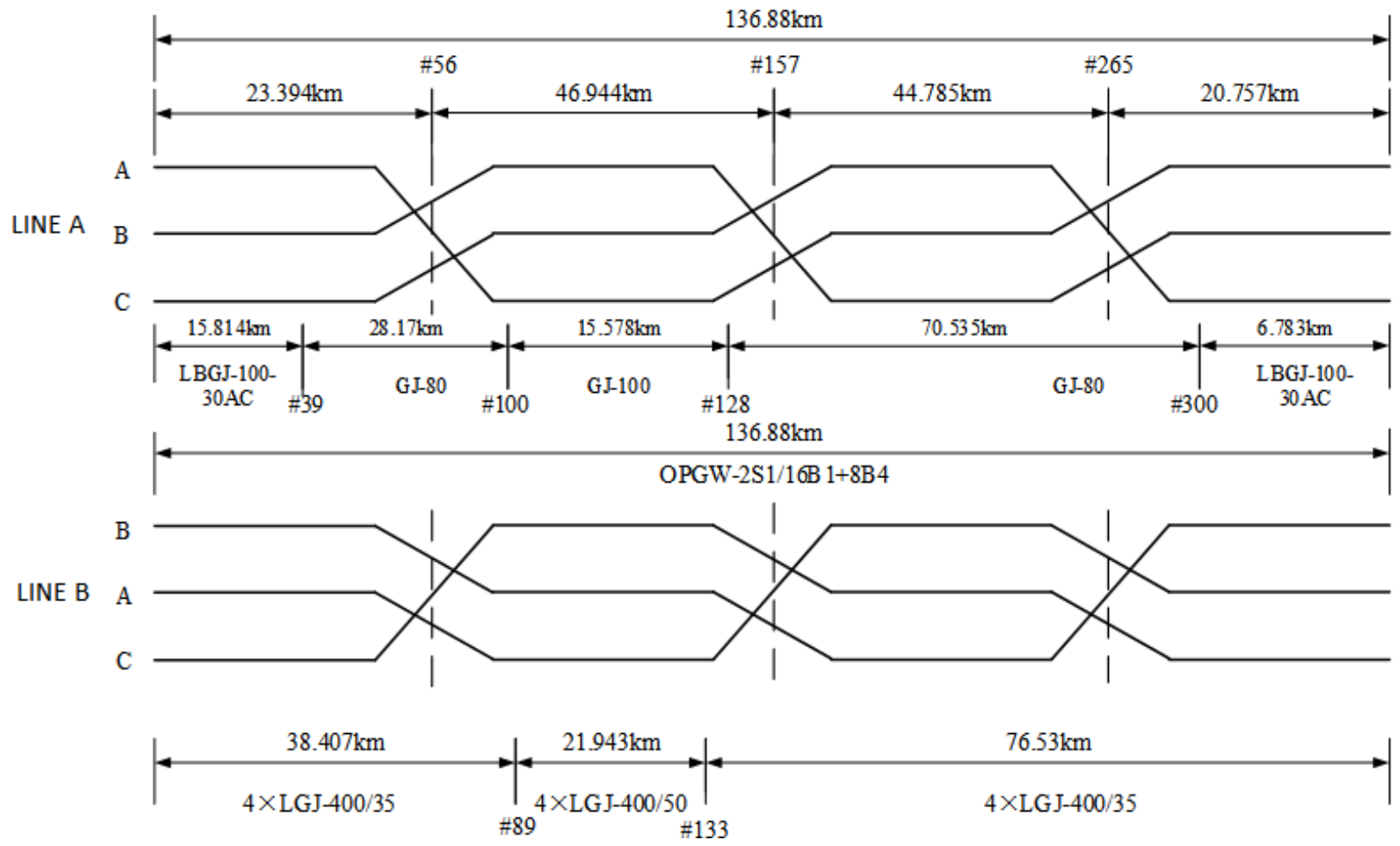

Figure 2. Wire transposition diagram

\section{Inductive Current Calculation Results and Analysis}

Based on the large-scale operation data of the power grid in, the ac system was equivalent to $500 \mathrm{kV}$ bus lines at $\mathrm{L}$ substation and $G$ substation respectively with the tidal current calculation program BPA. The equivalent self-impedance was $\mathrm{Z1}$ and $\mathrm{Z} 2$, and the equivalent mutual impedance was Z3, as shown in Figure 3.

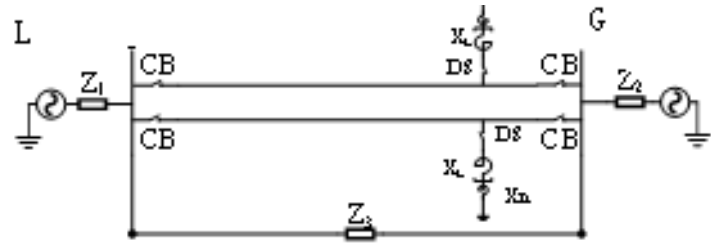

Figure 3. Calculation model

We used 6-phase PI equivalent model to simulate 500 $\mathrm{kV}$ double-circuit lines on the same tower. According to the equivalent results and line parameters, a simplified equivalent electromagnetic transient calculation model of $500 \mathrm{kV}$ LG A-B line is established in the electromagnetic transient program ATP-EMTP. 
According to the model, we calculate the current flowing through the reactor disconnector of the outage line, when one of the $500 \mathrm{kV}$ LG A-B lines is outage and the other is in operation. In the simulation calculation, the influence of transmission power, operation voltage, ground wire height and neutral reactance on induction current are analyzed.

\subsection{The influence of transmission power}

The bus voltage at both ends of the running line is $525 \mathrm{kV}$, and the calculation results of the induced current flowing through reactor disconnector of the outage line under different transmission power are shown in Figure 4.

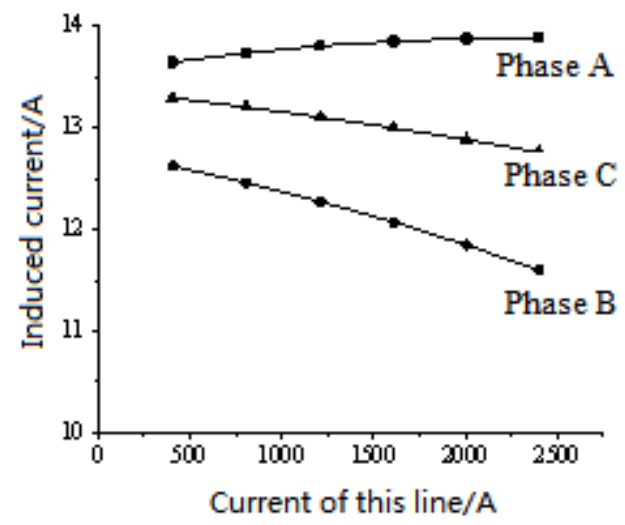

Figure 4. Current flowing through the disconnector

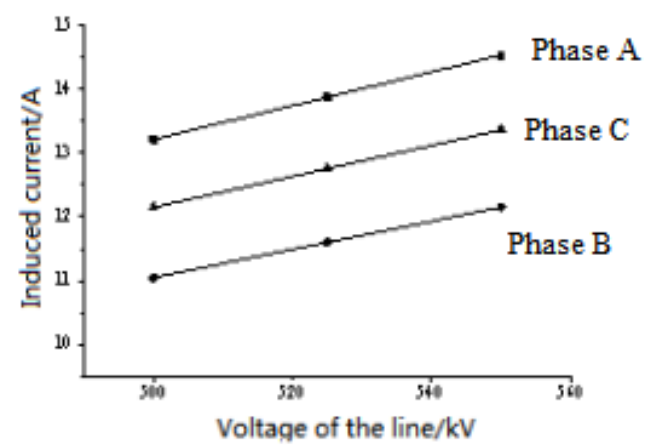

Figure 5. Current flowing through the disconnector

\subsection{The influence of the voltage of the line}

When the running line current is $1700 \mathrm{~A}$, We changed the bus voltage at both ends, the current flowing through reactor disconnector of the outage line is shown in Figure 5.

The results showed that with the increase of operating line voltage, the induced current of each phase of the outage line increased in direct proportion. It is further verified that the induced current is mainly affected by the electrostatic induction component.

\subsection{The influence of the height of the wire to the ground}

The terrain of $500 \mathrm{kV}$ LG A-B line is complex, with plains and mountains. It is difficult to accurately simulate and calculate the average distance to the ground. In this paper we studied the influence of the line height on the induced current, by adjusting the height of the tower or the sag of the line and changing the height of the line. The calculation results are shown in Figure 6.

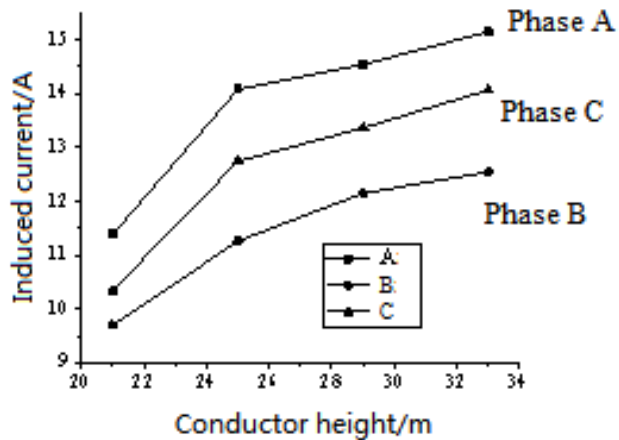

Figure 6. Current flowing through the disconnector

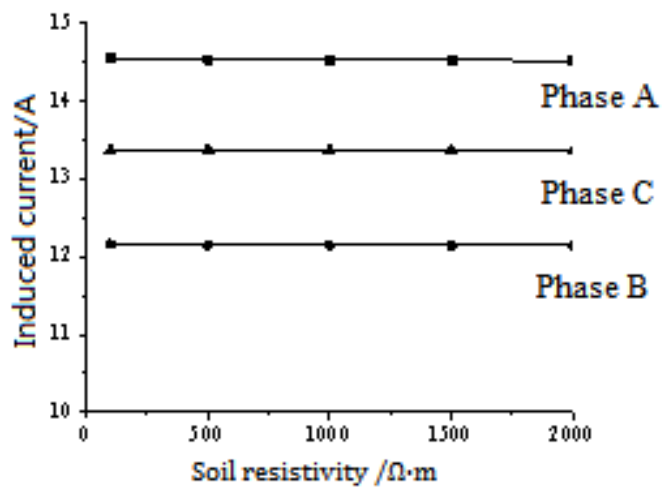

Figure 7. Current flowing through the disconnector

We can see that with the increase of wire height, the inductive current flowing through the reactor disconnector of the outage line increases, but the increasing trend becomes slower.

\subsection{Effect of soil resistivity}

The soil resistivity along the $500 \mathrm{kV}$ LG A-B transmission line varies greatly. There are 1 base tower with soil resistivity less than $100 \Omega \cdot \mathrm{m}, 84$ base tower with soil resistivity ranging from $100 \Omega \cdot \mathrm{m}$ to $500 \Omega \cdot \mathrm{m}, 77$ base tower with soil resistivity ranging from $500 \Omega \cdot \mathrm{m}$ to $1000 \Omega \cdot \mathrm{m}, 57$ base tower with soil resistivity ranging from $1000 \Omega \cdot \mathrm{m}$ to $2000 \Omega \cdot \mathrm{m}$, and 104 base tower with soil resistivity greater than $2000 \Omega \cdot \mathrm{m}$.

Soil resistivity increased from $100 \Omega \cdot \mathrm{m}$ to $2000 \Omega \cdot \mathrm{m}$, and the induced current flowing through the reactor disconnector of the outage line remained basically unchanged. So soil resistivity had little effect on the induced current, as shown in Figure 7.

\subsection{Switching induced current capacity of the the reactor disconnector}

The ground capacitance of the outage line is reduced by the compensation of the reactor. The induction of the running line to the outage line is mainly electrostatic 
induction. The maximum current value of the reactor disconnector over the $500 \mathrm{kV}$ line $\mathrm{A}$ and $\mathrm{B}$ is calculated as shown in table 1 .

Table 1. Current flowing through the disconnector

\begin{tabular}{cccccc}
\hline \multicolumn{3}{c}{ Reactor disconnector of LG A line } & \multicolumn{3}{c}{ Reactor disconnector of LG B line } \\
\hline A & B & C & A & B & C \\
\hline $15.148 \mathrm{~A}$ & $12.543 \mathrm{~A}$ & $14.066 \mathrm{~A}$ & $13.587 \mathrm{~A}$ & $14.416 \mathrm{~A}$ & $12.864 \mathrm{~A}$ \\
\hline
\end{tabular}

In standard, there is no corresponding requirement for the switching induced current capacity of the the reactor disconnector. The disconnector is allowed to have a certain ability to switch low capacitive current (such as break bus) or low inductive current (such as break voltage transformer). Under rated voltage, the disconnector should be able to reliably switch inductive current $0.5 \mathrm{~A}$ and capacitor current $2.0 \mathrm{~A}$. The existing $\mathrm{HV}$ reactor disconnector can not meet the ability of switching induced current in type test. In order to make the disconnector have the ability of switching induced current in Table 1, it is necessary to reform the existing $\mathrm{HV}$ reactor disconnector, for example, reform the contacts or adding parallel interrupter, SF6 or vacuum interrupter can be used in the form. magnitude of the switching current, but also on the recovery voltage at both ends of the disconnector, especially on the transient recovery voltage at both ends after the current passes through zero arc extinction. When the growth rate of transient recovery voltage exceeds the recovery rate of dielectric strength, the fracture arc will reignite, which will lead to failure of interruption

Therefore, it is necessary to evaluate the transient recovery voltage at both ends disconnector. We use the established electromagnetic transient calculation model to simulate the transient recovery voltage of the reactor disconnector on $500 \mathrm{kV}$ LG A-B. The calculation results are shown in table 2 .

\section{Fracture recovery voltage of disconnector when switching ing $\mathrm{HV}$ reactor}

Whether the HV reactor can be successfully switched, in addition to the excision current, depends not only on the

Table 2. Transient recovery voltage (peak) when disconnector switchs high voltage shunt reactor

\begin{tabular}{lllll}
\hline Phase & \multicolumn{2}{c}{ Steady state recovery voltagerecovery voltage } & \multicolumn{2}{c}{ Transient recovery voltage } \\
\hline & Line A & Line B & Line A & Line B \\
\hline A & $55.38 \mathrm{kV}$ & $56.12 \mathrm{kV}$ & $121.78 \mathrm{kV}$ & $130.93 \mathrm{kV}$ \\
B & $54.19 \mathrm{kV}$ & $48.82 \mathrm{kV}$ & $119.17 \mathrm{~V}$ & $127.92 \mathrm{kV}$ \\
$\mathrm{C}$ & $51.38 \mathrm{kV}$ & $56.84 \mathrm{kV}$ & $136.3 \mathrm{kV}$ & $123.59 \mathrm{kV}$ \\
\hline
\end{tabular}

\section{Conclusion}

In this paper, we studied the induction current and transient recovery voltage of $\mathrm{HV}$ reactor disconnector in $500 \mathrm{kV} \mathrm{LG} \mathrm{A-B} \mathrm{double-circuit} \mathrm{line} \mathrm{with} \mathrm{the} \mathrm{same} \mathrm{tower}$ during one-circuit outage.We get the following conclusions:

1) The coupling between double circuit lines on the same tower with $\mathrm{HV}$ reactor is mainly electrostatic coupling. The induced current flowing through the HV reactor disconnector has almost no relationship with the soil resistivity along the line and the neutral reactance value of the outage line. It is slightly related to the change of the transmission power of the operation line. The height of line and the change of the voltage of the operation line have great influence on the induced current, which is proportional to the change.
2)For the $500 \mathrm{kV}$ LG line studied in this paper, the induced current of the $\mathrm{HV}$ reactor disconnector flowing through the outage line reaches $15 \mathrm{~A}$, which exceeds the existing disconnector technical conditions. It is necessary to consider the technical transformation of the existing $\mathrm{HV}$ reactor disconnector and carry out experimental verification.

3)The switches recovery voltage is calculated when the reactor disconnector switch the reactor,and the transient recovery voltage and the steady-state recovery voltage of the disconnector are derived.

\section{Author's brief introduction and contact information:}

Li Haisheng (1980), male, Shandong native, senior engineer, engaged in substation operation management. 
ZHang Jianquan(1983),male, Guangxi native, engineer, engaged in substation operation.

Fang Boyi(1987), male, Heilongjiang native, engineer, engaged in substation operation.

Liu Bin (1979), male, Hunan native, senior engineer, engaged in substation operation.

Feng Bin (1983), male, Shandong native, senior engineer, engaged in electromagnetic transient simulation and overvoltage calculation of power system.

\section{References}

1. FU Ch, RAO H, LI XL, et al.(2009) Development and Application of DC Deicer.J. Automation of Electric Power Systems,33:53-56.

2. XU SK, ZHAO J. (2008) Review of ice storm cases impacted seriously on power systems and de-icing technology.J. Southern Power System Technology, 2:1-6.

3. ZHANG X, ZHANG JS, TIAN J, et al. (2009) Influence Between DC Deicer and Commo-tower Transmission Lines.J. Antomation of Electric Power Systems, 33: 95-98.
4. ZHENG N,ZHENG B,BAN LG,et al . (2013) Research on Induced Voltage and Induced Current of $750 \mathrm{kV}$ Strong Coupling Parallel Single-Circuit Lines.J. Power System and Clean Energy,29:38-44.

5. HAN YH, HUANG XM, DU QSH. (2007) Induced Voltage and Current on Double Circuits with Same Tower.J.High Voltage engineering,33:140-142.

6. YAN WJ, ZHOU T. (2012) Calculation and Analysis of Induced Voltage and Current on Multi-circuit Transmission Line[J] . JiangSu Electrical Engineering, 31: 67-69.

7. WU ZH,ZHAO QB, XU SH, et al.(2012) Discussion on Induced Current Switching Test of High Voltage Earthing Switches with Auxiliary-interrupters.J. High Voltage Apparatus, 48:103-108.

8. WANG LT. (2016) Analysis on Overvoltage Caused by Vacuum Circuit Breakers Switching off Shunt Reactors and Its Suppression Measures Based on ATP-EMTP.J. High Voltage Apparatus, 52: 194-200.

9. WANG Lt,ZHAO QB.(2012) Test Study on Shunt Reactor Switching for High Voltage AC Circuit Breaker.J. High Voltage Apparatus,48:45-51. 